\title{
Screening for Cognitive Impairment in a Stroke Prevention Clinic Using the MoCA
}

\author{
Lauren M. Mai, Wieslaw Oczkowski, Gail Mackenzie, Anatoly Shuster, \\ Lauren Wasielesky, Arlene Franchetto, Michael Patlas, Demetrios J. Sahlas
}

\begin{abstract}
Background: Screening for cognitive impairment is recommended in patients with cerebrovascular disease. We sought to establish the incidence of cognitive impairment using the Montreal Cognitive Assessment (MoCA) in a cohort of consecutive patients attending our stroke prevention clinic (SPC), and to determine whether a subset of the MoCA could be derived for use in this busy clinical setting. Methods: The MoCA was administered to 102 patients. Incidence of cognitive impairment was compared to presenting complaint and final diagnosis. Extent of cerebral white matter changes (WMC) was rated using the Age Related White Matter Changes (ARWMC) scale in 80 patients who underwent neuroimaging. A subset of the three most predictive test elements of the MoCA was derived using regression analysis. Results: $63.7 \%$ of patients scored $<26 / 30$ on the MoCA, in keeping with cognitive impairment. This was unrelated to the final diagnosis or extent of WMC, although a trend for lower MoCA scores was observed in older patients. A miniMoCA subscore combining the clock drawing test, five-word delayed recall, and abstraction was highly correlated with the final MoCA score $(\mathrm{R}=0.901)$. A score of $<7 / 10$ using this 10 -point mini-MoCA identified cognitive impairment as defined by the MoCA with a sensitivity of $98.5 \%$, and a specificity of $77.6 \%$. Conclusions: Two-thirds of SPC patients demonstrated evidence for cognitive impairment, irrespective of their final diagnosis or the presence of WMC. A mini-MoCA comprised of the clock drawing test, five-word delayed recall, and abstraction represents a potential alternative to the full MoCA in this population.
\end{abstract}

RÉSUMÉ: Dépistage du déficit cognitif au moyen du MoCa dans une clinique de prévention de l'accident vasculaire cérébral. Contexte : Le dépistage d'un déficit cognitif est recommandé chez les patients atteints d'une maladie cérébrovasculaire. Notre but était d'évaluer l'incidence du déficit cognitif au moyen du test d'évaluation cognitive de Montréal (MoCa) dans une cohorte de patients consécutifs fréquentant notre clinique de prévention de l'accident vasculaire cérébral (CPAVC) et de déterminer si une forme abrégée du test MoCA pourrait être élaborée pour utilisation dans le contexte d'une clinique très achalandée. Méthode : Le MoCa a été utilisé chez 102 patients. L'incidence de déficit cognitif a été comparé au motif de consultation et au diagnostic final. L'ampleur des changements au niveau de la substance blanche (SB) a été évaluée au moyen de l'échelle Age Related White Matter Changes (ARWMC) chez 80 patients qui ont subi une neuroimagerie. Un sous-groupe des trois éléments les plus prédictifs de l'échelle MoCA ont été identifiés au moyen d'une analyse de régression. Résultats : 63,7\% des patients ont obtenu un score de moins de 26 sur 30 au MoCA, ce qui témoigne de la présence d'un déficit cognitif. Cette observation n'était pas reliée au diagnostic final ou à l'ampleur des changements au niveau de la substance blanche. Un score au mini-MoCA constitué du test du dessin de l'horloge, du rappel retardé de cinq mots et de l'abstraction était hautement corrélé au score final du MoCA $(\mathrm{R}=0,901)$. Un score de moins de 7 sur 10 à ce mini-MoCA de 10 points identifiait un déficit cognitif tel que défini par le MoCA, avec une sensibilité de 98,5\% et une spécificité de 77,6\%. Conclusions : Les deux-tiers des patients de la CPAVC avaient des signes de déficit cognitif, quelque soit leur diagnostic final ou la présence de changements au niveau de la SB. Un mini-MoCA constitué du test du dessin de l'horloge, du rappel retardé de cinq mots et de l'abstraction pourrait être une alternative au test MoCA complet dans cette population.

Can J Neurol Sci. 2013; 40: 192-197

Screening for cognitive impairment in patients attending a stroke prevention clinic (SPC) is considered best practice ${ }^{1}$. Twothirds of patients with a history of stroke will subsequently develop some degree of cognitive impairment ${ }^{2}$. Even in the absence of stroke, most patients referred to a SPC harbor multiple vascular risk factors, which are themselves associated with cognitive impairment ${ }^{3,4}$.

Evaluation of cognition is an important part of the neurological assessment. Identification of mild cognitive impairment (MCI) provides patients and their families with a greater awareness for potential functional limitations, and should trigger a workup for possible reversible causes. Acknowledging the likelihood for additional cognitive decline can motivate patients to address vascular risk factors. Moreover, quantitative screening tools provide a baseline for comparing future assessments. More severe cognitive impairment raises additional concerns, such as questions about driving safety, or treatment with cholinesterase inhibitors ${ }^{5}$.

The presence of cerebral white matter disease changes (WMC) on brain imaging in patients with vascular risk factors is

From the Department of Clinical Neurological Sciences (LMM), Western University, London; Division of Neurology (WO, DJS), Department of Medicine, McMaster University; Central South Ontario Regional Stroke Centre (WO, GM, DJS), Department of Radiology (AS, LW, AF, MP), Hamilton General Hospital, Hamilton Health Sciences, Hamilton, Ontario, Canada.

Received May 1, 2012. Final Revisions Submitted September 17, 2012. Correspondence to: Demetrios J. Sahlas, Hamilton General Hospital, Room 706, McMaster Wing, 237 Barton Street East, Hamilton, Ontario, L8L 2X2, Canada. Email: sahlas@mcmaster.ca. 
commonly regarded as evidence for subcortical ischemic vascular pathology $y^{6}$ and is associated with vascular cognitive impairment (particularly executive dysfunction) $)^{7,8}$ and dementia $^{9,10}$. However, white matter hyperintensities (WMH) are also commonly observed on magnetic resonance imaging (MRI) in patients without specific cognitive complaints, and are present in many "normal, healthy" elderly individuals ${ }^{11-13}$.

Typically, SPC patients are living in the community and responsible for managing their own often complex health care needs, such as multiple medications, possibly including blood glucose monitoring, and keeping various appointments. It is important to identify those individuals who may be unable to engage in a medical management plan because of memory deficits or problems comprehending instructions from health care providers.

Nevertheless, routine screening for cognitive impairment in SPCs remains widely under adopted. Patients harboring covert vascular cognitive impairment are unlikely to volunteer descriptions of problems with executive function, the cognitive domain most frequently affected in vascular cognitive impairment ${ }^{14}$. This is in contrast to patients who present with complaints of memory impairment, potentially representing the amnestic form of MCI preceding a diagnosis of Alzheimer's Disease.

The Montreal Cognitive Assessment (MoCA) was conceived for the detection of $\mathrm{MCI}$, and was originally validated in a memory clinic population ${ }^{15}$. Its use in stroke patients is favoured over the Mini-Mental State Exam (MMSE) in part due to greater emphasis on testing for executive dysfunction. Not surprisingly, a recent population-based study of patients with transient ischemic attack and stroke concluded that the MMSE underestimated MCI compared to the $\mathrm{MoCA}^{16}$. Using the MoCA in patients $\geq 1$ year after transient ischemic attack (TIA) or stroke was associated with a sensitivity $=77 \%$ and specificity $=83 \%$ for detecting $\mathrm{MCI}^{17}$.

However, not all patients referred to a SPC are diagnosed with a TIA or stroke, resulting in a mixed patient population in actual practice. Other factors, such as chronic subcortical ischemic WMC or incipient Alzheimer's Disease, may be present and unrelated to the presenting complaint. Our intent was to evaluate the use of the MoCA as a screening tool for cognitive impairment in a cohort of consecutive patients presenting to our Regional SPC.

The urgency to evaluate symptoms potentially representing TIAs often leads to high patient volumes in SPCs, resulting in less time for each patient than in memory clinics. The length of time needed to administer the full MoCA in such an environment is almost prohibitive. Although a MoCA can typically be administered in approximately 12 minutes, there are competing demands including stroke education, counseling for vascular risk factors, and coordination of several time-sensitive investigations. While it is acknowledged that evaluation of cognition is particularly relevant in conjunction with these activities, formal screening for cognitive impairment in most SPCs is typically deferred. A five minute cognitive assessment proposed in the Vascular Harmonization criteria has been described but was envisioned for use over the telephone and has not been validated in practice ${ }^{18}$. An additional objective of our study was to therefore identify the most predictive components of the MoCA, in order to support the feasibility of introducing a Mini-MoCA for use in this clinical setting in the future.

\section{METHODS}

The MoCA was administered to 102 out of 107 consecutive new patients assessed by the authors (DJS, WO) presenting to the Regional SPC for Central South Ontario at the Hamilton General Hospital, part of Hamilton Health Sciences. The MoCA was not administered to four patients who could not speak English, and one patient who was aphasic from a previous stroke. Patients were referred for suspected TIA, recent history of stroke, or for primary prevention due to vascular risk factors placing them at high risk for stroke. Approval for the study was obtained from the Research Ethics Board at Hamilton Health Sciences.

Participant data included the following possible confounders: i) English as a second language (ESL), ii) current diagnosis of a mood disorder (depression and/or anxiety), or iii) previous diagnosis of cognitive impairment or dementia. The mean MoCA scores of each group created by the possible confounder were compared to the remaining group through analysis of variance (ANOVA).

Brain imaging results were reviewed in all cases in which computed tomogram (CT) or MRI of the brain were available. The Age-Related White Matter Changes (ARWMC) rating scale was rated by two independent radiologists (AS, LW). Cases in which concordance was not achieved were adjudicated by a neuroradiologist (AF).

To determine if the subset of patients with neuroimaging results comprised a representative sample, MoCA scores and ages for the group with neuroimaging were compared to the group without neuroimaging using the F-test. Evaluation for differences between paired means of white matter scores by diagnosis was then made using the Tukey-Kramer test.

In order to derive a predictive subset from the twelve MoCA test elements (trails, cube, clock, etc.) linear regression analysis was performed, and the highest Pearson product (i.e. the most linear dependent) of all possible combinations of two or three test elements was taken as the predictive subset.

\section{RESUlts}

\section{Population Characteristics}

The age of the participants ranged from 27 to 92 years, with a mean age of $65.8+/$ - SD 15 years. Fifty-five out of 102 of the study participants were women. The mean score obtained on the MoCA was 22.2/30 ( \pm 5.3 ), with a median score of 23/30. (49/102 participants had an extra one point as part of their final score for not having completed more than a Grade 12 education.)

Sixty-five out of 102 patients scored $<26$ in keeping with a diagnosis of MCI, as per the cut-off in the original MoCA publication ${ }^{15}$. Of these, 30 participants scored $<20 / 30$ (within the range of the Alzheimer's dementia group in the original MoCA study) ${ }^{15}$.

Table 1 illustrates patient subgroups according to final diagnosis and vascular risk factors. Forty-eight percent of patients were confirmed to present with either TIA or stroke. Those patients with a final diagnosis of cognitive impairment were typically referred for transient episodes of confusion 
Table 1: Patient demographics (sex, age)

\begin{tabular}{c|c|c|c|c|c|c}
\hline & Stroke & TIA & Migraine & $\begin{array}{c}\text { Cognitive } \\
\text { Impairment }\end{array}$ & Epilepsy & Other \\
\hline $\mathbf{n}$ & 25 & 24 & 16 & 10 & 6 & 21 \\
\hline Women (\% subgroup) & $12(48 \%)$ & $12(50 \%)$ & $12(75 \%)$ & $6(60 \%)$ & $2(33 \%)$ & $10(48 \%)$ \\
\hline mean age (years) $\mathbf{S D}$ & $65.3 \pm 13.1$ & $66.3 \pm 14.8$ & $51.9 \pm 15.7$ & $76.0 \pm 11.1$ & $66.8 \pm 13.6$ & $70.3 \pm 11.8$ \\
\hline median MoCA score & 24 & 23 & 24.5 & 18.5 & 22 & 22 \\
\hline mean MoCA score $\mathbf{S D}$ & $22.5 \pm 5.5$ & $23.0 \pm 4.0$ & $23.9 \pm 4.7$ & $18.5 \pm 6.9$ & $22.8 \pm 5.7$ & $21.2 \pm 5.2$ \\
\hline$<12$ yrs educ (\% subgroup) & $12(48 \%)$ & $12(50 \%)$ & $9(56 \%)$ & $6(60 \%)$ & $3(33 \%)$ & $8(38 \%)$ \\
\hline Hypertension (\% subgroup) & $23(92 \%)$ & $17(71 \%)$ & $6(38 \%)$ & $7(70 \%)$ & $3(50 \%)$ & $14(67 \%)$ \\
\hline diabetes mellitus (\% subgroup) & $5(20 \%)$ & $3(13 \%)$ & $1(6 \%)$ & $2(20 \%)$ & $2(33 \%)$ & $5(24 \%)$ \\
\hline Dyslipidemia (\% subgroup) & $18(72 \%)$ & $15(63 \%)$ & $6(38 \%)$ & $7(70 \%)$ & $5(83 \%)$ & $15(71 \%)$ \\
\hline cigarette smoking (\% subgroup) & $7(28 \%)$ & $4(17 \%)$ & $5(31 \%)$ & $1(10 \%)$ & $2(33 \%)$ & $1(5 \%)$ \\
\hline
\end{tabular}

MoCA scores (median, mean), number of patients with less than 12 years of education, and proportion of patients with vascular risk factors (hypertension, diabetes mellitus, dyslipidemia, cigarette smoking) according to final diagnosis. TIA=transient ischemic attack; $\mathrm{SD}=$ standard deviation.

ultimately attributed to previously unrecognized cognitive impairment, while other patients harboured baseline cognitive impairment unrelated to their presenting symptoms.

"Other" represents five cases of vertigo, three cases of transient visual disturbances of uncertain etiology, two presyncopal events, two referrals for asymptomatic high risk patients, and one each of: unspecified chest pain, paraesthesias, peripheral neuropathy, fibromuscular dysplasia, myasthenia gravis, allergic reaction, generalized weakness, transient global amnesia, and hyperglycemia. There was no difference in the MoCA score with respect to final diagnosis (ANOVA, $\mathrm{p}=0.146$ ).

Of the 102 patients in our study, 62 patients had a CT scan of the head performed as part of their evaluation, 35 patients had an MRI brain, and 17 patients had both brain imaging studies (Table 2). White matter scores were not assigned for three patients who had studies performed at outside centres or for the 19 patients who had no brain imaging. The 80 patients with brain imaging available formed a representative group, with no statistically significant difference noted by F-test between the group with imaging and those without imaging for total MoCA score $(\mathrm{P}=0.202)$ or age $(\mathrm{P}=0.355)$.

\section{Age and MoCA Score}

Although a trend was observed between patient age and MoCA score (Figure), the correlation was not statistically significant $(r=0.208)$, likely due to greater variability in MoCA score with increasing age. When patients were grouped by decade of birth (Table 3), there was a decrease in the mean MoCA score with increasing decile of age (ANOVA, $\mathrm{p}=0.00008)$.

\section{Age, MoCA, and ARWMC Score}

Although a trend was observed between patient age and ARWMC score, the correlation was not statistically significant $(\mathrm{R}=0.551)$, likely due to greater variability in ARWMC score

Table 2: Patients with neuroimaging, mean age

\begin{tabular}{c|c|c|c|c|c|c}
\hline & Stroke & TIA & Migraine & $\begin{array}{c}\text { Cognitive } \\
\text { Impairment }\end{array}$ & Epilepsy & Other \\
\hline n with neuroimaging (\% subgroup) & $20(80 \%)$ & $21(88 \%)$ & $13(81 \%)$ & $8(80 \%)$ & $3(50 \%)$ & $16(76 \%)$ \\
\hline mean age (years) \pm SD & $64.8 \pm 13.9$ & $65.5 \pm 15.8$ & $55.5 \pm 14.6$ & $75.3 \pm 13.2$ & $76.0 \pm 6.9$ & $71.3 \pm 13.3$ \\
\hline median MoCA score & 25 & 23 & 24 & 18.5 & 21 & 21 \\
\hline mean MoCA score + SD & $22.4 \pm 6.1$ & $22.7 \pm 3.9$ & $23.1 \pm 4.8$ & $18.5 \pm 7.7$ & $24.0 \pm 3.6$ & $21.3 \pm 5.7$ \\
\hline <12 yrs educ (\% subgroup) & $10(50 \%)$ & $11(48 \%)$ & $9(69 \%)$ & $6(75 \%)$ & $1(33 \%)$ & $6(38 \%)$ \\
\hline Mean ARWMC \pm SD & $4.8 \pm 4.1$ & $4.1 \pm 4.2$ & $1.3 \pm 2.8$ & $6.3 \pm 4.4$ & $5.7 \pm 3.2$ & $3.4 \pm 3.2$ \\
\hline
\end{tabular}

MoCA scores (median, mean), number of patients with less than 12 years of education, and age-related white matter changes (ARWMC) scores according to final diagnosis. TIA=transient ischemic attack; $\mathrm{SD}=$ standard deviation. 


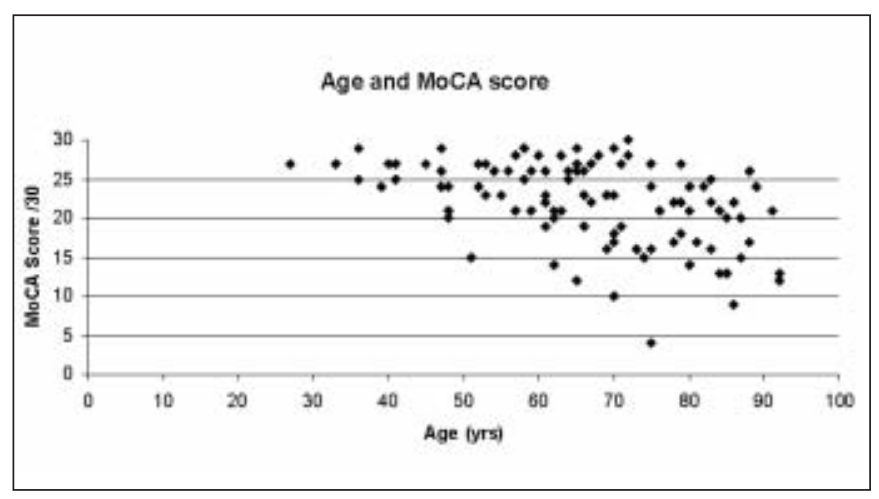

Figure: Scatter plot of age (years) versus the final Montreal Cognitive Assessment (MoCA) score in a cohort of stroke prevention clinic patients $(n=102)$.

with increasing age. Likewise, no correlation was observed between MoCA and ARWMC by linear regression analysis, $\mathrm{R} 2=0.18$.

\section{Possible Confounders}

The mean MoCA score in 9/102 participants for which English was their second language was lower than in the remainder of participants tested in their native language (17.2 \pm 5.6 vs. $22.7 \pm 5.0, \mathrm{P}$-value by T-test=0.019). Six of nine ESL participants were between the ages of 70-79, although the difference in mean age between these two groups was not statistically significant (70.3 \pm 9.5 vs. $65.8 \pm 14.9)$.

There was no difference in the mean MoCA between the 19 participants with a diagnosis of depression and/or anxiety and the remainder of the group $(21.9+/-5.5$ vs. $22.3+/-5.3$, T-test, $\mathrm{P}=0.807$ ). Finally, only four participants had a pre-existing diagnosis of cognitive impairment or dementia. The final diagnoses in this subgroup were TIA, stroke, symptoms related to cognitive impairment, and migraine.

\section{Finding a Predictive Subset}

The single test element most predictive of an abnormal MoCA score was delayed recall using five words ( $\mathrm{r}=0.715$, Table 4). The most predictive subset using two test elements involved the clock-drawing task and delayed recall using five words $(\mathrm{r}=0.835)$ and using three test elements involved the clock, delayed recall, and abstraction $(\mathrm{r}=0.901)$. By comparison, the five-minute neuropsychological protocol suggested in the National Institute of Neurological Disorders and StrokeCanadian Stroke Network Vascular Cognitive Impairment Harmonization Standards (delayed recall, phonemic fluency, and orientation $)^{18}$ was less predictive of an abnormal final score $(\mathrm{r}=$ $0.815)$.

Using an arbitrary score $\leq 7$ (out of a total possible score of 10) for the three test elements comprising the most predictive subset described above correlated well with a MoCA $\leq 26$ (sensitivity 0.985 , specificity 0.776 , PPV 0.855 , NPV 0.974 , Table 5). Only one false negative would result, although 11 false positives would be avoided using the full MoCA. Adding one
Table 3: Summary

\begin{tabular}{lccc}
\hline $\begin{array}{l}\text { Age } \\
\text { (years) }\end{array}$ & $n$ & mean MoCA score & variance \\
\hline$<\mathbf{5 0}$ & 17 & 25.1 & 7.0 \\
$\mathbf{5 0 - 5 9}$ & 15 & 24.5 & 12.6 \\
$\mathbf{6 0 - 6 9}$ & 27 & 23.2 & 19.3 \\
$\mathbf{7 0 - 7 9}$ & 22 & 20.8 & 44.3 \\
$\mathbf{> = 8 0}$ & 21 & 18.4 & 24.2 \\
\hline
\end{tabular}

Mean MoCA scores according to deciles of patient age.

point for $\leq 12$ years education decreased the sensitivity for a mini-MoCA score $\leq 7$ to $91.5 \%$, with only a modest increase in specificity (from $77.6 \%$ to $80.4 \%$ ).

\section{Discussion}

Our findings underscore the importance of routine screening for cognitive impairment in patients attending a SPC, given that $63.7 \%$ of the patients in our cohort demonstrated evidence for some degree of cognitive impairment, irrespective of the final diagnosis or the presence of WMC. In contrast, only $3.9 \%$ of patients had been previously diagnosed with either MCI or dementia, with the implication that cognitive impairment had previously gone unrecognized in the vast majority of cases.

Since the patients studied had experienced symptoms of neurological dysfunction, they could not be said to represent

Table 4: MoCA subtest, point contribution, and correlation to final MoCA score

\begin{tabular}{l|c|c|c}
\hline & $\begin{array}{c}\text { Point } \\
\text { Contribution }\end{array}$ & $\mathrm{R}^{2}$ & $\mathrm{R}$ \\
\hline Memory & 5 & 0.511 & 0.715 \\
\hline Naming & 3 & 0.462 & 0.680 \\
\hline Clock & 3 & 0.419 & 0.647 \\
\hline Serial 7 & 3 & 0.383 & 0.619 \\
\hline Abstraction & 2 & 0.378 & 0.615 \\
\hline Digit Span & 2 & 0.328 & 0.573 \\
\hline Orientation & 6 & 0.320 & 0.566 \\
\hline Letter A & 1 & 0.285 & 0.534 \\
\hline Trails & 1 & 0.284 & 0.533 \\
\hline Sentence Rep & 2 & 0.264 & 0.513 \\
\hline Fluency F & 1 & 0.257 & 0.507 \\
\hline Cube & 1 & 0.221 & 0.470 \\
\hline Education & 1 & 0.014 & 0.117 \\
\hline
\end{tabular}


healthy, community-dwelling individuals. However, most presented with transient symptoms and reported that they were back to their functional baseline. Since the use of the MoCA has not been validated in such a group, it remains to be established whether a lower cut-off score would more accurately discriminate patients with MCI, as has been suggested elsewhere ${ }^{19,20}$.

The likelihood of cognitive impairment appeared to be more closely associated with a patient's age than any other factor. The youngest group were those ultimately diagnosed with migraine aura as the cause for their presenting symptoms, a common reason for referral to $\mathrm{SPCs}^{21}$, although MoCA scores were comparable to patients in other diagnostic categories.

The lack of correlation between the MoCA and ARWMC scores may have been due to our relatively small sample size, in addition to not considering other factors such as measures of brain atrophy. A heterogenous group of patients will probably harbour multiple reasons for MCI, such as sleep apnea in younger, obese patients ${ }^{22}$ or incipient Alzheimer's Disease in older patients.

Our findings are comparable to normative data from a recent, large, population-based study of cardiovascular disease ${ }^{23}$. Most of our patients harbored vascular risk factors, regardless of the final diagnosis, which are closely linked with cognitive impairment ${ }^{24}$. There is evidence that optimization of vascular health in mid-life results in a lesser burden of subcortical white matter changes in late life ${ }^{25}$.

Recent data from 91 nondemented TIA and stroke patients in the Oxford Vascular Study (OXVASC) found that $42 \%$ met the Petersen criteria for $\mathrm{MCI}^{17}$. This cohort represented patients with a confirmed diagnosis of TIA or stroke $\geq 1$ year after initial presentation who provided consent to a neuropsychological battery taking approximately 50-60 minutes to administer. The greater prevalence of cognitive impairment in our own cohort is likely related to the absence of any selection bias, given that cognitive screening was performed on consecutive patients at the point of initial clinical contact, in accordance with current best practice recommendations ${ }^{1}$.

The MoCA has been recommended for cognitive screening of patients at risk for cerebrovascular disease in SPCs, but it remains to be established whether the time required to perform a full MoCA in every such patient is feasible in actual practice. A mini-MoCA comprised of three elements of the MoCA (clock drawing test, five-word delayed recall, abstraction) appears highly sensitive for predicting an abnormal MoCA score and pending validation, would be well-suited as a practical tool for screening of patients attending a SPC.

While a greater contribution to the final MoCA score is clearly influenced by the number of points for individual subtests, it is interesting to note that orientation (six points) was a relatively poor contributor to the final score. It was also unlikely that subtests contributing a single point would have a sizable impact on the final score. The validity of individual subtests should therefore be compared to independent cognitive measures as part of more complete neuropsychological testing.

Ultra-brief assessments for screening of cognitive impairment have previously been described ${ }^{26}$. Folstein developed a "micro" Mental Status Examination, which likewise included clockdrawing and delayed recall of a five word list ${ }^{27}$. More recently,
Table 5: False negatives and false positives in predicting the final MoCA score

\begin{tabular}{c|c|c|c|c}
\hline $\begin{array}{c}\text { Mini- } \\
\text { MoCA } \\
(/ 10)\end{array}$ & $\begin{array}{c}\text { Complete MoCA } \\
(/ 30)\end{array}$ & $\begin{array}{c}\text { False } \\
\text { Neg }\end{array}$ & $\begin{array}{c}\text { False } \\
\text { Pos }\end{array}$ & $\mathbf{n}$ \\
\hline 10 & $\mathbf{2 9}(28.2,29.8)$ & 0 & 0 & 4 \\
\hline 9 & $\mathbf{2 7 . 5 ( 2 6 . 8 , 2 8 . 2 )}$ & 0 & 0 & 12 \\
\hline 8 & $\mathbf{2 7}(26.3,27.7)$ & 1 & 0 & 11 \\
\hline 7 & $\mathbf{2 4 . 5}(23.4,25.6)$ & 0 & 8 & 17 \\
\hline 6 & $\mathbf{2 3 . 7}(22.5,24.9)$ & 0 & 3 & 13 \\
\hline 5 & $\mathbf{2 1 . 6}(20.5,22.8)$ & 0 & 0 & 11 \\
\hline 4 & $\mathbf{2 0 . 2 ( 1 8 . 7 , 2 1 . 6 )}$ & 0 & 0 & 11 \\
\hline 3 & $\mathbf{1 7 . 2 ( 1 5 . 7 , 1 8 . 7 )}$ & 0 & 0 & 12 \\
\hline 2 & $\mathbf{1 4 . 3}(12.9,15.7)$ & 0 & 0 & 6 \\
\hline 1 & $\mathbf{8 . 3}(3.8,12.9)$ & 0 & 0 & 3 \\
\hline 0 & $\mathbf{1 1 . 5}(8.6,14.4)$ & 0 & 0 & 2 \\
\hline
\end{tabular}

Predicting the final MoCA score using a mini-MoCA score $\leq 7 / 10$ comprised of clock drawing (3), delayed recall (5), and abstraction (2)

the National Institute of Neurological Disorders and StrokeCanadian Stroke Network Vascular Cognitive Impairment Harmonization Standards suggested using three components of the MoCA (delayed recall of a five word list, phonemic fluency, and orientation $)^{18}$ which appear to be less predictive of an abnormal final MoCA score, based on the cohort of patients we tested.

In conclusion, the high probability of identifying patients with cognitive impairment presenting to a SPC argues for the development of a brief, practical, and accurate screening tool. The development of a mini-MoCA using clock drawing, delayed recall of a five word list, and abstraction has the potential to fulfill this role, but remains to be validated with proper neuropsychological testing. Normative data for the MoCA in this population is lacking, so that results should be interpreted with caution. Inferences regarding the etiology of cognitive impairment in this population should likewise be deferred until further cognitive evaluation and appropriate investigations can be completed, and should also involve probing for actual functional limitations, patient education, and counseling.

\section{ACKNOWLEDGMENTS}

Permission was granted for use of the MoCA in this research project. The authors would also like to thank Nicholas G. Davies for providing computer programming support, as well as Alicja Koper, RN, for assistance in preparing the data for publication.

\section{SOURCES OF FUNDING}

Dr. Sahlas is supported by the MG DeGroote Professorship in Stroke Management, McMaster University. 


\section{REFERENCES}

1. Lindsay MP, Gubitz G, Bayley M, et al. Canadian Best Practice Recommendations for Stroke Care (Update 2010). On behalf of the Canadian Stroke Strategy Best Practices and Standards Writing Group. 2010; Ottawa, Ontario Canada: Canadian Stroke Network.

2. Jin YP, Di Legge S, Ostbye T, Feightner JW, Hachinski V. The reciprocal risks of stroke and cognitive impairment in an elderly population. Alzheimers Dement. 2006;2:171-8.

3. Duron E, Hanon O. Vascular risk factors, cognitive decline, and dementia. Vasc Health Risk Manag. 2008;4:363-81.

4. Martinic-Popovic I, Lovrencic-Huzjan A, Demarin V. Assessment of Subtle Cognitive Impairment in Stroke-Free Patients with Carotid Disease. Acta Clin Croat. 2009;48:231-40.

5. Malouf R, Birks J. Donepezil for vascular cognitive impairment. Cochrane Database of Systematic Reviews 2004, Issue 1. Art. No.: CD004395.

6. Roberts JS, Karlawish JH, Uhlmann WR, Peterson RC, Green RC. Mild cognitive impairment in clinical care: A survey of American Academy of Neurology members. Neurology. 2010; 75:425-31.

7. Mok VC, Wong KA, Lam WW, et al. Cognitive impairment and functional outcome after stroke associated with small vessel disease. J Neurol Neurosurg Psychiatry. 2004;75:560-6.

8. Au R, Massaro JM, Wolf PA, et al. Association of white matter hyperintensity volume with decreased cognitive functioning: The Framingham Heart Study. Arch Neurol. 2006;63:246-50.

9. de la Torre JC. Cerebral hypoperfusion, capillary degeneration, and development of alzheimer disease. Alzheimer Dis Assoc Disord. 2000;14:S72-81.

10. Schmidt R, Ropele S, Enzinger C, et al. White matter lesion progression, brain atrophy, and cognitive decline: The Austrian Stroke Prevention Study. Ann Neurol. 2005;58:610-6.

11. Longstreth WT, Jr., Dulberg C, Manolio TA, et al. Incidence, manifestations, and predictors of brain infarcts defined by serial cranial magnetic resonance imaging in the elderly: The cardiovascular health study. Stroke. 2002;33:2376-82.

12. Soderlund H, Nilsson LG, Berger K, et al. Cerebral changes on MRI and cognitive function: The Cascade Study. Neurobiol Aging. 2006;27:16-23.

13. Vermeer SE, Longstreth WT, Jr., Koudstaal PJ. Silent brain infarcts: A systematic review. Lancet Neurol. 2007;6:611-9.

14. O'Sullivan M, Morris RG, Huckstep B, Jones DK, Williams SC, Markus HS. Diffusion tensor MRI correlates with executive dysfunction in patients with ischaemic leukoaraiosis. J Neurol Neurosurg Psychiatry 2004;75:441-7.

15. Nasreddine ZS, Phillips NA, Bedirian V, et al. The Montreal Cognitive Assessment, MoCA: a brief screening tool for mild cognitive impairment. J Am Geriatr Soc. 2005;53:695-9.
16. Pendlebury ST, Cuthbertson FC, Welch SJ, Mehta Z, Rothwell PM. Underestimation of cognitive impairment by mini-mental state examination versus the montreal cognitive assessment in patients with transient ischemic attack and stroke: a populationbased study. Stroke. 2010;41:1290-3.

17. Pendlebury ST, Mariz J, Bull L, Mehta Z, Rothwell PM. MoCA, ACE-R, and MMSE Versus the National Institute of Neurological Disorders and Stroke-Canadian Stroke Network Vascular Cognitive Impairment Harmonization Standards Neuropsychological Battery After TIA and Stroke. Stroke. 2012; 43:464-9.

18. Hachinski V, Iadecola C, Petersen RC, et al. National Institute of Neurological Disorders and Stroke: Canadian Stroke Network vascular cognitive impairment harmonization standards. Stroke. 2006;37:2220-41.

19. Godefroy O, Fickl A, Roussel M, et al. Is the Montreal Cognitive Assessment superior to the Mini-Mental State Examination to detect poststroke cognitive impairment? A study with neuropsychological evaluation. Stroke. 2011;42:1712-6.

20. Dong YH, Venketasubramanian N, Chan BPL, et al. Brief screening tests during acute admission in patients with mild stroke are predictive of vascular cognitive impairment 3-6 months after stroke. J Neurol Neurosurg Psychiatry 2012;83:580-5.

21. Vujovic-Zotovic N, Sahlas DJ, Norris JW. Acute migraine attacks misdiagnosed as transient ischemic attacks. Canadian Journal of Neurological Sciences 2003;30 Suppl. 2:S76.

22. Engleman HM, Kingshott RN, Martin SE, Douglas NJ. Cognitive function in the sleep apnea/hypopnea syndrome (SAHS). Sleep. 2000;23:S102-8.

23. Rossetti HC, Lacritz LH, Cullum CM, Weiner MF. Normative data for the Montreal Cognitive Assessment (MoCA) in a populationbased sample. Neurology. 2011;77:1272-5.

24. Unverzagt FW, McClure LA, Wadley VG, et al. Vascular risk factors and cognitive impairment in a stroke-free cohort. Neurology. 2011;77:1729-36.

25. Kivipelto M, Solomon A, Rovio $\mathrm{S}$, et al. Changes in vascular risk factors from midlife to late life and white matter lesions: a 20year follow-up study. Dement Geriatr Cogn Disord. 2011;31: $119-25$.

26. Ismail Z, Rajji TK, Shulman KI. Brief cognitive screening instruments: an update. Int J Geriatr Psychiatry. 2010;25:111-20.

27. Rapp MA, Rieckmann N, Gutzmann H, Folstein MF. Micro-Mental Test - a short method of dementia screening. Der Nervenarzt. $2002 ; 73: 839-44$ 